\title{
MOLECULAR DIVERSITY AND PHYLOGENETIC ANALYSIS OF EIGHT DROMEDARY CAMEL BREEDS OF PAKISTAN BASED ON MITOCHONDRIAL ATP6 AND ATP8 GENES
}

\author{
Rizwan Ali ${ }^{1, \dagger}$, Tanveer Hussain ${ }^{2, *, \dagger}$, Masroor Ellahi Babar ${ }^{2}$, Faiza Masood $^{3}$, Nisar Ahmad \\ Muhammad Tariq Pervez ${ }^{4}$ and Ahmed Nawaz
}

\author{
${ }^{1}$ Centers for Biomedical engineering, University of Science and Technology of China, Hefei, Anhui, China; \\ ${ }^{2}$ Department of Molecular Biology, Virtual University of Pakistan, Lahore, Pakistan; ${ }^{3}$ University of Veterinary and \\ Animal Sciences, Lahore, Pakistan; ${ }^{3}$ Lasbela University of Agriculture, Water and Marine Sciences, Utthal, \\ Balochistan, Pakistan; ${ }^{4}$ Department of Bioinformatics and Computational Biology, Virtual University of Pakistan, \\ Lahore, Pakistan. \\ ${ }^{\dagger}$ Authors contributed equally \\ "Corresponding author's e-mail: tanveer.hussain@vu.edu.pk
}

\begin{abstract}
This work was designed to detect genetic polymorphism in mitochondrial ATP6 and ATP8 genes in eight Pakistani camel breeds (Camelus dromedarius) including Mareecha, Barela, Kachi, Kharani, Thari, Pahari, Watni and Mix-bred (nondescriptive). The genetic relationships among the selected breeds belonging to miscellaneous geographical regions were also carried out through sequences of selected genes. A total of 842 bp including full CDS of both ATP6 and ATP 8 genes showed 11 polymorphic sites in all the selected camel breeds. Five polymorphic sites were single variable and six were found parsimony informative sites. The neighbor joining phylogenetic tree was constructed through MEGA 6 program. All Pakistani camel breeds were confirmed as dromedaries. The phylogenetic tree with 23 other mammalian species reconfirmed the classical biological classification. To the best of our knowledge this is the earliest report on selected genes in Pakistani dromedary camel breeds.
\end{abstract}

Keywords: Dromedary camel, ATP6 and ATP8 genes, polymorphisms, phylogenetics.

\section{INTRODUCTION}

Camel (Camelus dromedaries) is an animal of immense economic value, providing useful products and services e.g. milk, wool, meat and drought power to mankind. Camels have high forbearance ability adjacent to a very harsh, severe and dehydration-prone environment (Schwartz, 1992; Yaqoob and Nawaz, 2007). Camel has rare physiological characteristics; their body temperatures may fluctuate from 34 to $42.1^{\circ} \mathrm{C}$ during the whole day, they may tolerate loss of water more than $32 \%$ and their ability to store more than 100 liter of drinking water in their body (Jasra and Mirza, 2005). Due to these qualities, they have a unique ability to adapt the desert lifestyle.

Pakistani camel is of two types, riverine and mountain/hilly. Now, there are 21 documented breeds of camels in Pakistan. Camels of seven breeds are present in Balochistan province in of Pakistan i.e. Brahvi, Kachhi, Kharani, Lassi, Makrani, Pishin, Rodbari, whereas, in Khyber Pakhtunkhwa, four breeds i.e. Gaddi, Ghulmani, Khader and Maya, in Punjab, there are five breeds i.e. Bagri, Barela or Thalocha, Cambelpuri, Kala-Chitta and Mareecha and four breeds are documented in Sindh province of Pakistan i.e. Dhatti, Khari, Larri or Sindhi and Sakrai. Out of these, Mareecha, Dhatti,
Larri, Sakrai are riverine type while Kohi, Cambelpuri are mountain/hilly sort of animals (Heston et al., 1985; Isani and Baloch, 2000)

The mitochondrial (mt) DNA can be used as a best marker to study the phylogeny almost in all mammalian species, due to its mutation rate as compared to nuclear DNA (Avise, 1994; Stanley et al., 1994). The mtDNA becomes most appropriate target for some of genetic studies (Galtier et al., 2009) The mitochondrial genome of Bactrian camel has 16,680 bp (Cui et al., 2007). Selected mt ATP6 and ATP8 genes are involved in energy production in unicellular and multi-cellular organisms. The mammalian mitochondrion consists of 16 subunits through which mtATP6 and ATP8 genes are essential. Research on mutations in mitochondrial genes explains the evolution process in detail (Di Rocco et al., 2009). In the current study, mitochondrial genes i.e. ATP6 and ATP8 were sequenced for understanding the evolutionary relationship of eight camel breeds found in Pakistan. Conducting research on the camel genome will help to identify genes of great importance, that will make clear that how camels has adjusted themselves in their harsh habitat (Schwartz, 1992; Al-Swailem et al., 2007). 


\section{MATERIALS AND METHODS}

Sample collection and DNA extraction: Blood samples from 79 true representative animals from the eight different camel breeds (Barela, Mareecha, Kachi, Kharani, Pahari, Thari, Watni and Mix-bred) were collected from various government livestock farms and from their respective home tracts in different regions of the country. The DNA was extracted by inorganic method of extraction as described by Sambrook et al. (1989) and Hussain et al. (2015). Extracted DNA samples were quantified through NanoDrop 2000/2000c (Thermo Scientific USA).

Primer designing: Specific primers were designed from NCBI, GenBank sequence database (www.ncbi.nlm.nih.gov) given in Table 1. The camel sequence (accession Number: JN632608, Camelus dromedarius isolate Morocco mitochondrion, complete genome) was used as reference for this study. The size of ATP 8 gene is $204 \mathrm{bp}$ followed by ATP 6 gene of 681 bp. Both the genes are continuous with overlapping region of $43 \mathrm{bp}$. Primers were designed by Primer fox software (www.primerfox.com). The total product size of the primer pair was $890 \mathrm{bp}$ (Table 2)

Table 1. Length of mitochondrial ATP 6 and $A T P 8$ genes with overlapping region.

\begin{tabular}{lc}
\hline Region & Length (bp) \\
\hline ATP synthase subunit 8 gene & $204 \mathrm{bp}$ \\
ATP synthase subunit 6 gene & $681 \mathrm{bp}$ \\
Overlapping region & $43 \mathrm{bp}$ \\
\hline
\end{tabular}

Table 2. Mitochondrial ATP8 and ATP6 Genes Primer Pair for Pakistani dromedary camel.

\begin{tabular}{llc}
\hline Primers & 5' to 3' Sequence & Product size \\
\hline CdATP8/6-F & AGCCATGACCCCTCCTTAGT & $890 \mathrm{bp}$ \\
CdATP8/6-R & TGGTATGCGTGAGTCTGGTG & \\
\hline
\end{tabular}

Amplification, sequencing and software analysis: Primers were found best at annealing temperature of $54^{\circ} \mathrm{C}$ using standard PCR protocol using final reaction mixture of $25 \mu \mathrm{L}$. PCR products were run on $1.2 \%$ gel electrophoresis and positive samples were precipitated using absolute ethanol before sequencing using ABI Genetic Analyzer 3130 xL (San Diego California) through Sanger's sequencing method.

All the sequences were aligned with the help of online software blast 2 sequence (http/www.ncbi.nlm.nih.com) and the sequences analysis and polymorphism identification were detected using CodonCode Aligner. The Neighbor Joining phylogenetic trees were constructed from the final consensus sequences with help of MEGA 6 program package (Tamura et al., 2013). The neighbour joining phylogenetic tree was constructed among eight studied breeds of camel on the basis of consensus sequences of ATP6 and ATP 8 genes from each breed. Support for individual branch of phylogenetic tree was assessed by Bootstrap percentages computed after 1000 replicates. The Pakistani breeds were compared with dromedary, domestic and wild Bactrian camel sequences from other parts of the world along with sequences of different mammalian species already reported on GenBank, NCBI (Table 3). DnaSP software package was used to identify the haplotype and nucleotide diversities and analysis of nucleotide polymorphisms (Librado and Rozas, 2009)

Table 3.ATP6 and ATP8 sequences of different Mammalian species obtained from GenBank, NCBI and used for phylogenetic analysis with dromedary camel breeds of Pakistan.

\begin{tabular}{|c|c|c|}
\hline Animal & Species & $\begin{array}{l}\text { GenBank } \\
\text { Accession No. }\end{array}$ \\
\hline Arabian Camel & Camelus dromedaries & JN632608 \\
\hline Bactrian Camel & Camelus bactrianus & AP003423 \\
\hline Wild Bactrian & Camelus bactrianus & EF507800 \\
\hline Camel & ferus & \\
\hline Guanaco & Lama guanicoe & EU681954 \\
\hline Vicugna & Vicugna icugna & FJ45689 \\
\hline Llama & Lama glama & AP003426 \\
\hline Alpaca & Lama pacos & NC002504 \\
\hline Cattle (humped) & Bos indicus & JN817303 \\
\hline $\begin{array}{l}\text { Cattle (non- } \\
\text { humped) }\end{array}$ & Bos taurus & HQ025805 \\
\hline Domestic yak & Bos grunniens & GQ464260 \\
\hline American bison & Bison bison & GU946998 \\
\hline Water Buffalo & Bubalus bubalis & NC006295 \\
\hline Domestic goat & Capra hircus & NC005044 \\
\hline Sheep & Ovis aries & NC001941 \\
\hline Peruvian guemal & $\begin{array}{l}\text { Hippocamelus } \\
\text { antisensis }\end{array}$ & JN632646 \\
\hline Gray brocket & Mazama gouazoupira & JN632658 \\
\hline Red brocket & Mazama Americana & JN632657 \\
\hline White tailed deer & $\begin{array}{l}\text { Odocoileus } \\
\text { virginianus }\end{array}$ & JN632672 \\
\hline Barasingha & Rucervus duvaucelii & JN632696 \\
\hline $\begin{array}{l}\text { Mesopotamian } \\
\text { fallow deer }\end{array}$ & Dama mesopotamica & JN632630 \\
\hline Yarkland deer & $\begin{array}{l}\text { Cervus elaphus } \\
\text { yarkandensis }\end{array}$ & GU457435 \\
\hline $\begin{array}{l}\text { Formosan Sika } \\
\text { deer }\end{array}$ & $\begin{array}{l}\text { Cervus Nippon } \\
\text { taiouanus }\end{array}$ & EF058308 \\
\hline Human & Homo sapiens & JF896800 \\
\hline
\end{tabular}

\section{RESULTS}

Genetic variations: After sequencing and alignment a total of 842 bp region of both ATP6 and ATP 8 genes in all eight camel breeds were obtained. No deletion/insertion mutations were found. A total 29 mutations were detected on 11 different polymorphic sites. Five sites were singleton variable sites at position $153,202,249,374$, and 572, while six sites 216, 290 , 
447, 593, 779 and 785 were found parsimony informative sites. A total of nine haplotypes were generated from all sequences in eight camel breeds. The haplotype $(\mathrm{Hd})$ and nucleotide diversity $(\mathrm{Pi})$ were $0.5290 \pm 0.1010$ and $0.00181 \pm$ 0.00047 respectively. Because all sequences obtained from different geographical regions across the country, the Tajima's D value -1.33564 designated signature of population's expansion.

The average number of nucleotide difference in all studied camel breeds were K: 1.52605. Haplotype 1 included Thari, Kharani and Pahari. Haplotype 2 included Kachi. Haplotype 3 was shared by three camel breeds Watni, Mix-bred and Mareecha. Haplotype 4 has a single breed Barela, Haplotpe 5 included Barela, Haplotype 6 have a single Mix-bred, Haplotype 7 included Mix-bred, Haplotype 8 included Mareecha camel and Haplotype 9 also included Mareecha camel breed.

Mareecha and Mix-bred represent three haplotyes (Hap3, Hap8, Hap9 and Hap3, Hap6, Hap7 respectively), while Barela showed two haplotypes (Hap4 and Hap5) and the remaining five camel breeds Pahari (Hap1), Kachi (Hap2), Thari (Hap1), Watni (Hap3) and Kharani (Hap1) revealed one haplotype. Haplotype1 is shared by three camel breeds including Thari, Kharani and Pahari while Haplotype3 is shared by Watni, Mix-bred and Mareecha breed.

Phylogenetic analysis: The phylogenetic results showed the genetic relatedness of these breeds as the Mareecha and Pahari camel breeds of the Punjab are grouped together. Similarly, the camel breeds sampled from Balochistan province of Pakistan are also grouped close to each other i.e. Thari, Watni, Kharani and Kachhi (Fig. 1).

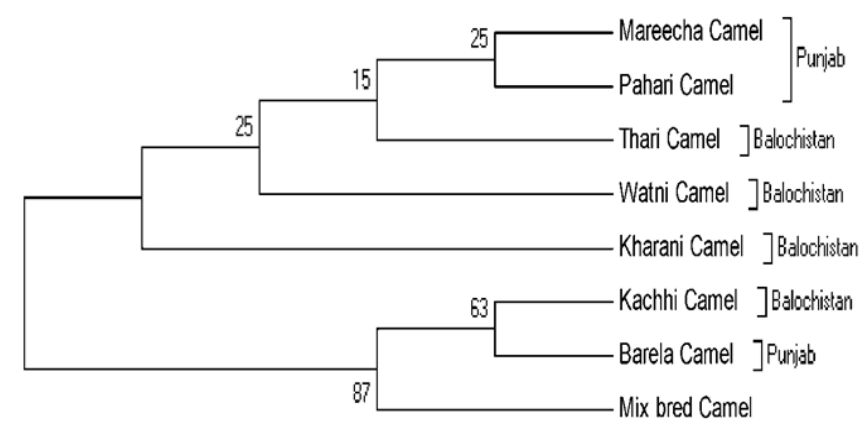

Figure 1. Phylogenetic tree of Pakistani Camel breeds (Province wise) based on ATP6 and ATP8 gene sequences using MEGA 6.1 (Neighbor-Joining Tree) using 1000 bootstrap value (rectangular view).

The ATP8 and ATP6 genes sequence data of studied breeds was compared with reported sequence data (available in GenBank NCBI). The Sheep (Ovis aries) ATP8 and ATP6 sequence was selected as outer group. All studied single humped camel of Pakistan (Camelus dromedarius) grouped together along with Arabian camel (Camelus dromedarius) sequence. The two humped camels (Camelus bactrianus) were also grouped together in another clade, confirming the genetic differences between two types of camel (Fig. 2).

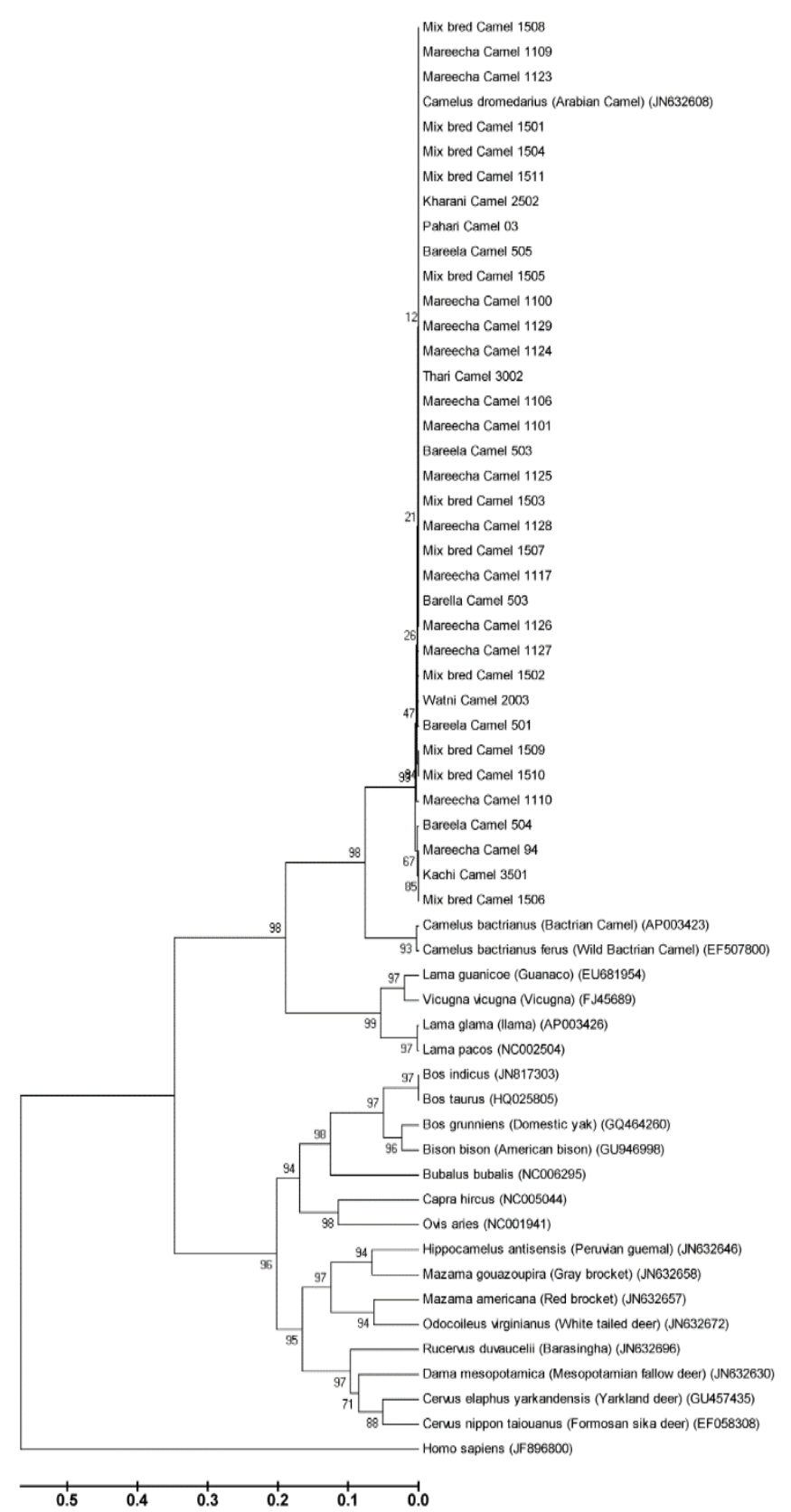

Figure 2. Neighbor Joining tree of selected camel breeds of Pakistan with other reported sequences from different mammalian species, constructed using MEGA 6.1. 


\section{DISCUSSION}

The phylogenetic tree based on consensus sequences of eight Pakistani camel breeds gave an idea about their close genetic relationships. The tree was somehow following the geographical distances as the breeds from Balochistan and Punjab were grouped separately. Barela from Punjab and Kachhi from Balochistan showed closeness in the phylogeny they are found in close vicinity, therefore there might be chances of cross breeding between both breeds followed by the migration of local people from one area to other (Fig. 1). There have been some studies on phylogeny of camel in the world based on mitochondrial genome, in which $C y t b$ and Dloop region of mitochondria were evaluated and phylogenetic relationships were also recognized among sub-species of South American Camelids, in which they included sequences of three of the four sub-species of Lama guanicoe (guanaco) and both of the Vicugna vicugna (vicuña) as well to check the relatedness, similar to the current study (Irwin et al., 1991; Stanley et al., 1994; Palma et al., 2001). Another South American Camelid study, which validated the use of control region of mitochondrial genome as a molecular biomarker to deduce data on Camelid genetic relationships and population biodiversity (Mate et al., 2004). Similarly, nucleotide sequence of a polyubiquitin gene (PUBC1) of (Camelus dromedarius) was also used to have an insight of genetic diversity in one of the Arabian camel study, which revealed that there are genetic variation, one of the $325 \mathrm{bp}$ motif was 95 and $88 \%$ identical to human polyubiquitin genes B and C respectively and synonymous mutations were observed, while their amino acid sequence was $100 \%$ homologous (AlKhedhairy, 2004). Microsatellite markers can also be served as a tool for determining population diversity, one of the Egyptian studies revealed that RAPD markers results showed genetic variation between and within different camel breeds. The phylogenetic relationship among the five camel breeds showed two groups. The first group includes Maghrabi, Baladi and Mowallad, while the second group of Sudani and Somali. This study showed that Mowallad breed was very close to both Baladi and Maghrabi which confirm the origin of Mowallad as a hybrid between Baladi and Maghrabi breeds (Mahrous et al., 2011).

Another phylogenetic tree was constructed in the current study using haplotypes from Pakistani camel along with other species. The one clade in the phylogenetic tree was consisted of single humped camel (C. dromedarius) i.e. Pakistani and Arabian camel and two humped camel (C. bactrianus), while the next clade consisted of the biological cousins of camel i.e. Lama (Lama glama), Guanaco (L. guanicoe) and Vicugna (Vicugna icugna).

The second major branch of the phylogenetic tree consisted of all other mammals. This major branch was further divided into two sub branches i.e. Bovine family representing cattle i.e. Bos taurus (non-humped cattle) and Bos indicus (humped cattle) together, Yak (Bos grunniens) and American bison (Bison bison) together, then buffalo (Bubalus bubalis), the sheep (Ovis aries) and goat (Capra hircus) together. One of similar sort of Mongolian domestic bacterian camel study demonstrate that their local bacterian camel are in close relatedness to Chinese bactrian and dromedries (Chuluunbat et al., 2014). One of the phylogenetic study of domestic and wild-type camels revealed that extant wild type two-humped camel may not share common ancestors with bactrian domestic camels is not the same sub-species in their maternal origins (Cui et al., 2007; Ji et al., 2009).

The second sub branch was consisting of other mammal species i.e. Peruvian guemal (Hippocamelus antisensis), Gray brocket (Mazama gouazoupira), Red brocket (Mazama americana), white tailed deer (Odocoileus virginianus) as they were grouped together. Similarly, the Barsingha (Rucervus duvaucelii), Mesopotamian fallow deer (Dama mesopotamica), Yarkland deer (Cervus elaphus yarkandensis) and Formosan Sika deer (Cervus Nippon taiouanus) were also grouped together (Fig. 2).

The ATP6 and ATP8 genes sequence of human (Homo sapiens) were taken as outer group and it clearly differed and separated from rest of the phylogenetic tree leaves i.e. camel, bovine, ovine, caprine and other mammals.

Conclusion: Our results on the genetic architecture of Pakistani camel breeds produced base-line information on camel genetics. In general, the low genetic distances between the studied breeds can give an insight about their origin and evolution. This may clarify genetic relationships between and among different camel breeds. This study may be used to design proper breeding and conservation policies for camel in Pakistan to save this important genetic resource of the country.

Acknowledgements: Sample collection was important issue in the commencement of this research work, so authors really appreciate the whole staff at Camel Breeding and Research Station (CBRS), Rakh Mahni, District Bkakkar, Pakistan. We specially pay our gratitude to Dr. Muhammad Ashraf Iqbal, who helped us in sample collection.

Note: The extended abstract of this paper was published in the proceedings of the 4th international conference on Sustainable Animal Agriculture for Developing Countries (SAADC), 27-31 July, 2013 at Lanzhou, China.

\section{REFERENCES}

Al-Khedhairy, A.A.A. 2004. Characterization of the nucleotide sequence of a polyubiquitin gene (PUBC1) from Arabian camel, Camelus dromedarius. BMB Rep. 37:144-147.

Al-Swailem, A.M., K.A. Al-Busadah, M.M. Shehata, I.O. AlAnazi and E. Askari. 2007. Classification of Saudi 
Arabian camel (Camelus dromedarius) subtypes based on RAPD technique. J. Food Agric. Environ. 5:143-148.

Avise, J.C. 1994. Molecular markers, Natural history and evolution. Chapman \& Hall, New York; pp.44-91.

Hussain, T., M.E. Babar, A. Wajid, A. Nawaz, A. Nadeem, S.A. Shah, M.A. Shahid, N. Ahmad, K. Javed and M. Abdullah. 2015. Mitochondrial cytochrome-b and Dloop sequence based genetic diversity in Mareecha and Bareela camel breeds of Pakistan. J. Anim. Plant Sci. 25:591-594

Chuluunbat, B., P. Charruau, K. Silbermayr, T. Khorloojav and P. Burger. 2014. Genetic diversity and population structure of Mongolian domestic Bactrian camels (Camelus bactrianus). Anim. Genet. 45:550-558.

Cui, P., R. Ji, F. Ding, D. Qi, H. Gao, H. Meng, J. Yu, S. Hu and H. Zhang. 2007. A complete mitochondrial genome sequence of the wild two-humped camel (Camelus bactrianus ferus): An evolutionary history of camelidae. BMC Genomics 8:241-244.

Di Rocco, F., A. Zambelli and L.V. Rioja. 2009. Identification of camelid specific residues in mitochondrial ATP synthase subunits. J. Bioenerget. Biomemb. 41:223-228.

Galtier, N., B. Nabholz, S. Glémin and G. Hurst. 2009. Mitochondrial DNA as a marker of molecular diversity: A reappraisal. Mol. Ecol. 18:4541-4550.

Heston, A., H. Hasnain, S. Hussain and R. Khan. 1985. The economics of camel transport in Pakistan. Econ. Dev. Cult. Change 34:121-141.

Irwin, D.M., T.D. Kocher and A.C. Wilson. 1991. Evolution of the cytochromeb gene of mammals. J. Mol. Evol. 32:128-144.

Isani, G.B. and M.N. Baloch. 2000. Camel breeds of Pakistan. The Camel Applied Research and Development Network (CARDN), NADRI, Islamabad, Pakistan.

Jasra, A.W. and M.A. Mirza. 2005. Camel production systems in Asia. In: R. Cardellino, A. Rosati and C. Mosconi (eds.), Current Status of Genetic Resources, Recording and Production Systems in African, Asian and. American camelids. FAO/ICAR Seminar on Camelids; ICAR Technical Series No. 11, Sousse, Tunisia, May 30, 2004; pp.37-49.

Ji, R., P. Cui, F. Ding, J. Geng, H. Gao, H. Zhang, J. Yu, S. $\mathrm{Hu}$ and H. Meng. 2009. Monophyletic origin of domestic Bactrian camel (Camelus bactrianus) and its evolutionary relationship with the extant wild camel (Camelus bactrianus ferus). Anim. Genet. 40:377-382.

Librado, P. and J. Rozas. 2009. DnaSP v5: A software for comprehensive analysis of DNA polymorphism data. Bioinform. 25:1451-1452.

Mahrous, K.F., H.A. Ramadan, S.H. Abdel-Aziem and M. Mordy. 2011. Genetic variations between camel breeds using microsatellite markers and RAPD techniques. J. Appl. Biosci. 39:2626-2634.

Maté, M., F. Di Rocco, A. Zambelli and L. Vidal-Rioja. 2004. Mitochondrial DNA structure and organization of the control region of South American camelids. Mol. Ecol. Notes 4:765-767.

Palma, R.E., J.C. Marin, A.E. Spotorno, J.L. Galaz, M. Gerken and C. Renieri. 2001. Phylogenetic relationships among South American subspecies of camelids based on sequences of the cytochrome b mitochondrial genes. Pub. Europ. Assoc. Anim. Prod. 105:44-52.

Sambrook, J., E.F. Fritsch and T. Maniatis. 1989. Molecular cloning: A laboratory manual. Cold Spring Harbor Laboratory Press, Cold Spring Harbor, NY; pp.18-47.

Schwartz, H. 1992. Productive performance and productivity of dromedaries (Camelus dromedarius). Anim. Res. Dev. 35:86-98.

Stanley, H.F., M. Kadwell and J.C. Wheeler. 1994. Molecular evolution of the family camelidae: A mitochondrial DNA study. Proc. Royal Soc. London B: Biol. Sci. 256:1-6.

Tamura, K., G. Stecher, D. Peterson, A. Filipski and S. Kumar. 2013. MEGA6: Molecular evolutionary genetics analysis version 6.0. Mol. Biol. Evol. 30:2725-2729.

Yaqoob, M. and H. Nawaz. 2007. Potential of Pakistani camel for dairy and other uses. Anim. Sci. J. 78:467-475. 